\title{
Effects of Complexant Concentration in Base Solution on the Structure and Electrochemical Properties of $\mathrm{LiNi}_{0.8} \mathrm{Co}_{0.1} \mathrm{Mn}_{0.1} \mathrm{O}_{2}$
}

\author{
Jing WANG ${ }^{*}$, Ang GAO, Ran WANG, Yuefeng SU, Shi CHEN, Feng WU \\ School of Materials Science \& Engineering \\ Beijing Institute of Technology \\ Beijing, China \\ e-mail: wangjingbit98@bit.edu.cn
}

\begin{abstract}
LiNi}_{0.8} \mathrm{Co}_{0.1} \mathrm{Mn}_{0.1} \mathrm{O}_{2}$ powders were synthesized from co-precipitated spherical metal hydroxide, $\mathrm{Ni}_{0.8} \mathrm{Mn}_{0.1} \mathrm{Co}_{0.1}(\mathrm{OH})_{2}$. The effects of the complexant $\left(\mathrm{NH}_{4} \mathrm{OH}\right)$ concentration in base solution on the microstructure, crystalline structure and electrochemical properties of the product were studied. The results of scanning electron microscopy showed that the particle morphology was more regular and the particle size tended to increase with improving the concentration of $\mathrm{NH}_{4} \mathrm{OH}$. The as-prepared material had a good $\alpha-\mathrm{NaFeO}_{2}$ hexagonal lamellar structure, as confirmed by $\mathrm{X}$-ray diffraction pattern, the sample had the least $\mathrm{Li}^{+} / \mathrm{Ni}^{2+}$ cation disorder when the concentration of $\mathrm{NH}_{4} \mathrm{OH}$ was $1.5 \mathrm{M}$, which contributing to good cycle performance, its initial discharge capacity achieved $198.5 \mathrm{mAh}^{-1}$ and the capacity retention rate was $95 \%$ after 50 cycles at $0.2 \mathrm{C}$ between 2.8 and $4.3 \mathrm{~V}$.
\end{abstract}

Keywords-complexant; co-precipitation; $\mathrm{LiNi}_{0.8} \mathrm{Co}_{0.1} \mathrm{Mn}_{0.1} \mathrm{O}_{2}$; lithium-ion batteries

\section{INTRODUCTION}

In order to meet the fast-growing demand of electric vehicles (EVs) and plug-in hybrid electric vehicles (PHEVs), lithium-ion batteries (LIBs) with higher energy density and longer lifespan are indispensable and thus the cathode materials with high storage capacity are in urgent demand. Among the cathode materials, nickel-rich layered materials have been intensively investigated for their high capacity, high energy density and low cost. ${ }^{[1-4]}$ A large number of researchers have made a detailed study of the synthesis mechanism of some nickel-cobalt-manganese hydroxide in ammonia complexes. ${ }^{[5,6]}$ At present, the industrialized method to prepare nickel-rich layered materials is mainly coprecipitation method. However, the morphology, the tap density and the electrochemical performance of these prepared products using this method are significantly dependent on the synthetic conditions. Zhang compared the properties of the products synthesized at different temperatures and found the composites synthesized at $60^{\circ} \mathrm{C}$ had the highest initial discharge capacity and cycling capacity. ${ }^{[7]}$ Noh studied the morphology of the precursors prepared at different agitation speeds. ${ }^{[8]}$ It was found that the secondary particles were formed from the well-developed primary nanoplates at low stirring speed, but the shape was irregular. The secondary particles became more regular and dense when the stirring speed rose to $1000 \mathrm{r} / \mathrm{min}$. Lee found that the appropriate increase in complexant concentration $\left(\mathrm{NH}_{4} \mathrm{OH}\right)$ was conducive to the formation of uniform spherical secondary particles. ${ }^{[9]}$ In our work, we studied the effect of the complexant concentration in base solution on the properties of $\mathrm{LiNi}_{0.8} \mathrm{Co}_{0.1} \mathrm{Mn}_{0.1} \mathrm{O}_{2}$, which has not been studied so far.

\section{EXPERIMENTAL SESSION}

\section{A. Synthesis Method}

$\mathrm{Ni}_{0.8} \mathrm{Mn}_{0.1} \mathrm{Co}_{0.1}(\mathrm{OH})_{2}$ was synthesized by continuous hydroxide co-precipitation process in the flask at $55^{\circ} \mathrm{C}$ under $\mathrm{Ar}$ atmosphere protection. Initially, the reactor was filled with $50 \mathrm{~mL}$ distilled water of different complexant concentration as the base solution, and then the $2 \mathrm{~mol} / \mathrm{L}$ metal salts solution (mol\% of $\left.\mathrm{NiSO}_{4} \cdot 6 \mathrm{H}_{2} \mathrm{O}: \mathrm{CoSO}_{4} \cdot 7 \mathrm{H}_{2} \mathrm{O}: \mathrm{MnSO}_{4} \cdot 5 \mathrm{H}_{2} \mathrm{O}=8: 1: 1\right), 2 \mathrm{~mol} / \mathrm{L}$ $\mathrm{NaOH}$ and $\mathrm{NH}_{4} \mathrm{OH}$ mixed solution were fed into the reactor at the same time, the $\mathrm{pH}$ was adjusted to 11.0 by adjusting the flow rate of the mixed solution and the stirring speed was stable at $600 \mathrm{rpm}$. The $\mathrm{Ni}_{0.8} \mathrm{Co}_{0.1} \mathrm{Mn}_{0.1}(\mathrm{OH})_{2}$ precursor powder was filtered, washed with deionized water, and vacuum-dried at $80{ }^{\circ} \mathrm{C}$ for $24 \mathrm{~h}$. The dried $\mathrm{Ni}_{0.8} \mathrm{Co}_{0.1} \mathrm{Mn}_{0.1}(\mathrm{OH})_{2}$ was mixed with $\mathrm{Li}_{2} \mathrm{CO}_{3}(5 \mathrm{~mol} \%$ excess amount), then the mixed powder was sintered at $550{ }^{\circ} \mathrm{C}$ for 5 $\mathrm{h}$ preliminarily and then calcined for $15 \mathrm{~h}$ at $750{ }^{\circ} \mathrm{C}$ in $\mathrm{O}_{2}$ to obtain $\mathrm{LiNi}_{0.8} \mathrm{Co}_{0.1} \mathrm{Mn}_{0.1} \mathrm{O}_{2}$. The samples prepared by different complexant concentration in base solution, $0 \mathrm{M}$, $1.5 \mathrm{M}, 3 \mathrm{M}$, named as $\mathrm{S} 0, \mathrm{~S} 1.5$ and $\mathrm{S} 3$, respectively.

\section{B. Material Characterization}

The morphology of the as-prepared samples were performed by field emission scanning electron microscopy (FESEM, Hitachi S-4800). Powder X-ray diffraction (XRD, Rigaku UltimaIV-185) was used to measure the crystal structure of all the samples with $\mathrm{Cu}-\mathrm{K} \alpha$ radiation at a scan rate of $8^{\circ} 2 \theta / \mathrm{min}$. Transmission electron microscopy (TEM) and high-resolution transmission electron microscopy (HRTEM) were operated upon a JEOL JEM-2100 instrument.

\section{Electrochemical Measurement}

The electrochemical properties were measured in the CR2025 coin type cells for all samples. Pasting the mixture of $10 \mathrm{wt} \%$ acetylene black, $80 \mathrm{wt} \%$ active materials, and 10 wt\% PVDF onto a current collector (aluminum foil) to 
prepare the cathode. The electrolyte was $1 \mathrm{~mol} \cdot \mathrm{L}^{-1} \mathrm{LiPF}_{6} /$ $(\mathrm{EC}+\mathrm{DMC})(1: 1$ in volume $)$ solution. The cells were assembled in an argon-filled glovebox. The electrochemical test started running between 2.8 and $4.3 \mathrm{~V}$ (versus $\mathrm{Li} / \mathrm{Li}^{+}$) on a CT2001A Land instruments after cells had been aged for 24h. The electrochemical impedance spectroscopy (EIS) for all the samples was measured by a CHI604D electrochemical workstation with a frequency range of $100 \mathrm{kHz}$ to $0.01 \mathrm{~Hz}$.

\section{RESUlTS AND DISCUSSION}

In the growth of precursor particles, the two processes, nucleation and crystal growth, compete with each other which determine the morphology of the product. The precursor will appear as a small particle that composed of flocculation or colloidal if the nucleation process is dominate; whereas, the well-grown, larger and regular spherical precursor particles will be obtained. In the absence of ammonia, the reaction rate of nickel-cobalt manganese ions with hydroxide ions is very fast, which causes the nucleation process dominating, and only the small particles with flocculation or colloid can be obtained, generally. When the ammonia molecule is present in the metal ion solution, the nickel-cobalt-manganese ion will form a complex with ammonia, and thus the degree of freedom of the nickelcobalt-manganese ion is reduced, which inhibits the nucleation rate and promotes the crystal growth. Therefore, the control of ammonia concentration can affect the size and morphology of the final products directly.

The $\mathrm{NH}_{4} \mathrm{OH}$ in the solution can be combined with transition metal ions and reduce the degree of supersaturation of the reaction solution, which retard the rate of nucleation and influence the morphology of hydroxide precursors. Fig.
1 illustrate the morphologies of the precursors and asprepared materials. It is obviously observed that the honeycomb precursors are composed of a large number of fine striplike primary particles. The honeycomb structure is favorable for the interdiffusion of $\mathrm{Li}^{+}$within the nanoplates during the high temperature calcination, which is conducive to the uniform composition distribution of the final product, and also reserve enough space for crystal growth. Also, there is a serious effect of the concentration of $\mathrm{NH}_{4} \mathrm{OH}$ in base solution on the particle morphology, size, and distribution. With the concentration increasing, the particles become much more spherical, the particle size distribution become narrower and the primary particles stack more closely. Most of the precursor particle size distribut between 5-7 $\mu \mathrm{m}$ of S3 sample. After sintering, the thickness of primary nanoplates increases and the quasi-spherical morphology is preserved.

The crystal structure of all samples were characterized by XRD that shown in Fig. 2a. The reflections for asprepared materials are indexed to the layered hexagonal $\alpha$ $\mathrm{NaFeO}_{2}$ structure with $\mathrm{R} \overline{3} \mathrm{~m}$ space group and the clear splits of $(006) /(102)$ and $(108) /(110)$ peaks signify a high degree layered structure. ${ }^{[10,11]}$ The integrated intensity ratios of $I_{(003)} / I_{(104)}$ for these three samples are 1.05, 1.34 and 1.08, respectively, indicating that S1.5 has the least undesirable $\mathrm{Li}^{+} / \mathrm{Ni}^{2+}$ cation disorder. ${ }^{[12]}$ TEM, HRTEM (high resolution TEM) and FFT (fast Fourier transformed) images of S1.5 are shown in Fig. 2b-c. Fig. 2b implies the particles are stacked by irregular primary nanoplates. The measured lattice fringes with the interlayer spacing of $0.475 \mathrm{~nm}$ are assigned to (003) planes of layered $\mathrm{R} \overline{3} \mathrm{~m}$ phase which also verified by the FFT pattern, implying the as-prepared sample is structurally uniform and well-crystallized.
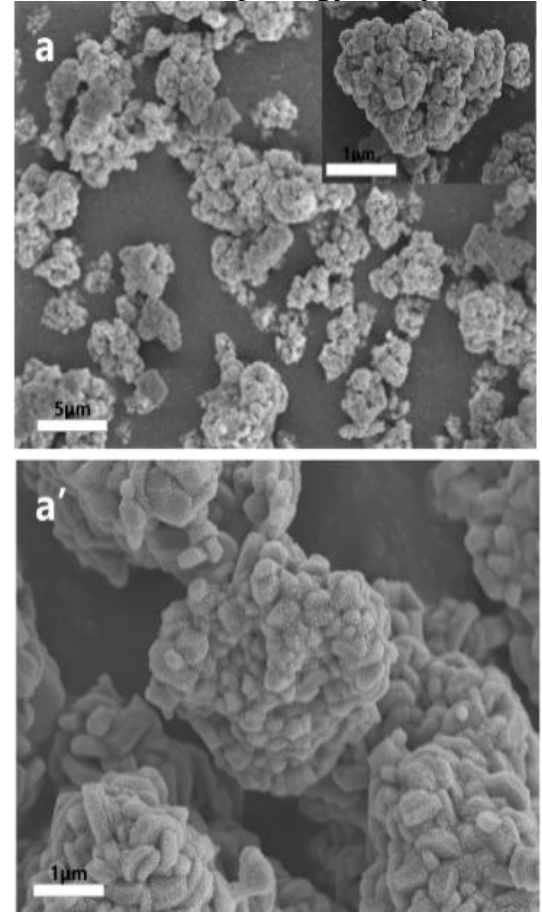
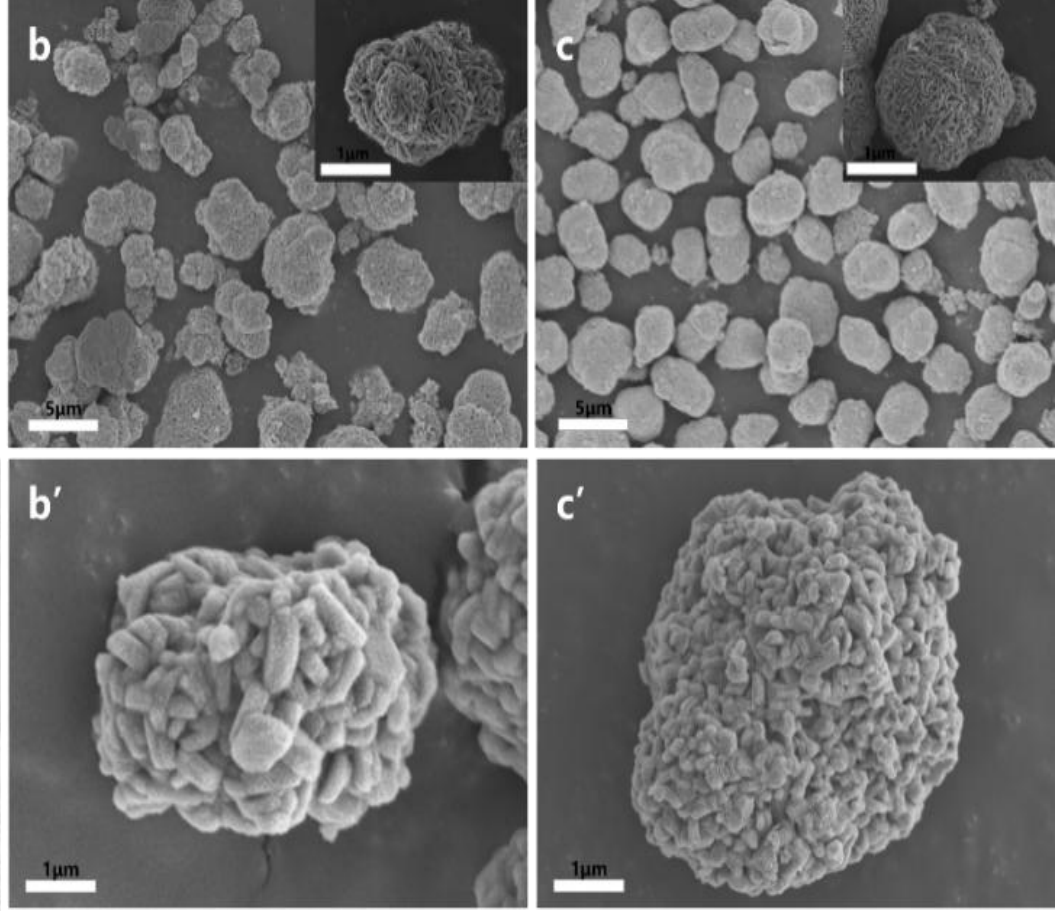

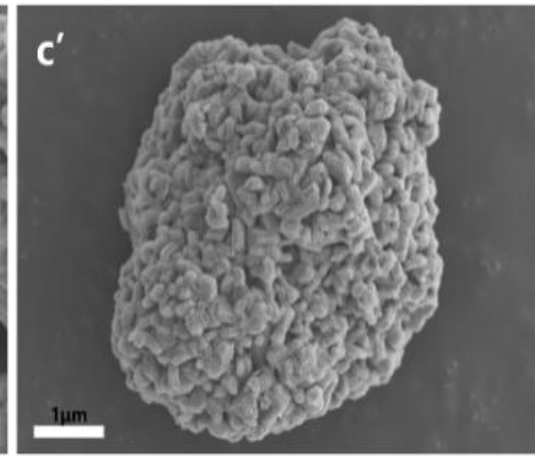

Figure 1. SEM images of $\mathrm{Ni}_{0.8} \mathrm{Co}_{0.1} \mathrm{Mn}_{0.1}(\mathrm{OH})_{2}$ (up) and $\mathrm{LiNi}_{0.8} \mathrm{Co}_{0.1} \mathrm{Mn}_{0.1} \mathrm{O}_{2}$ (down); (a, a') 0M; (b, b') 1.5M; (c, c') 3M. 

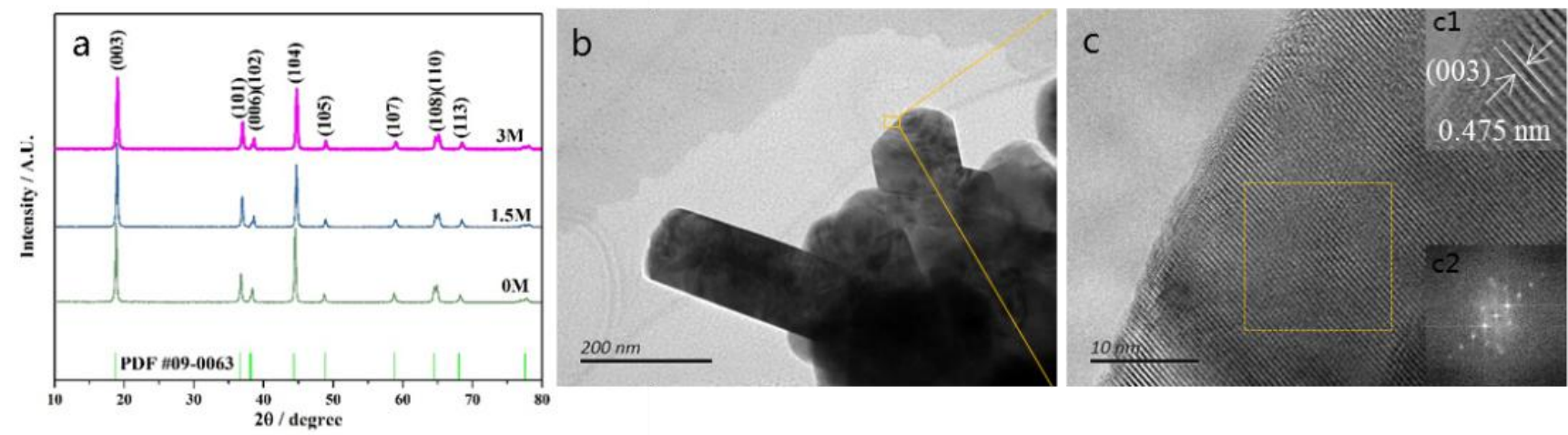

Figure 2. (a) XRD patterns of samples S1, S1.5 and S3; (b) TEM image of S1.5 and (c) HRTEM image in (b); (c2) FFT image of selected region in (c).
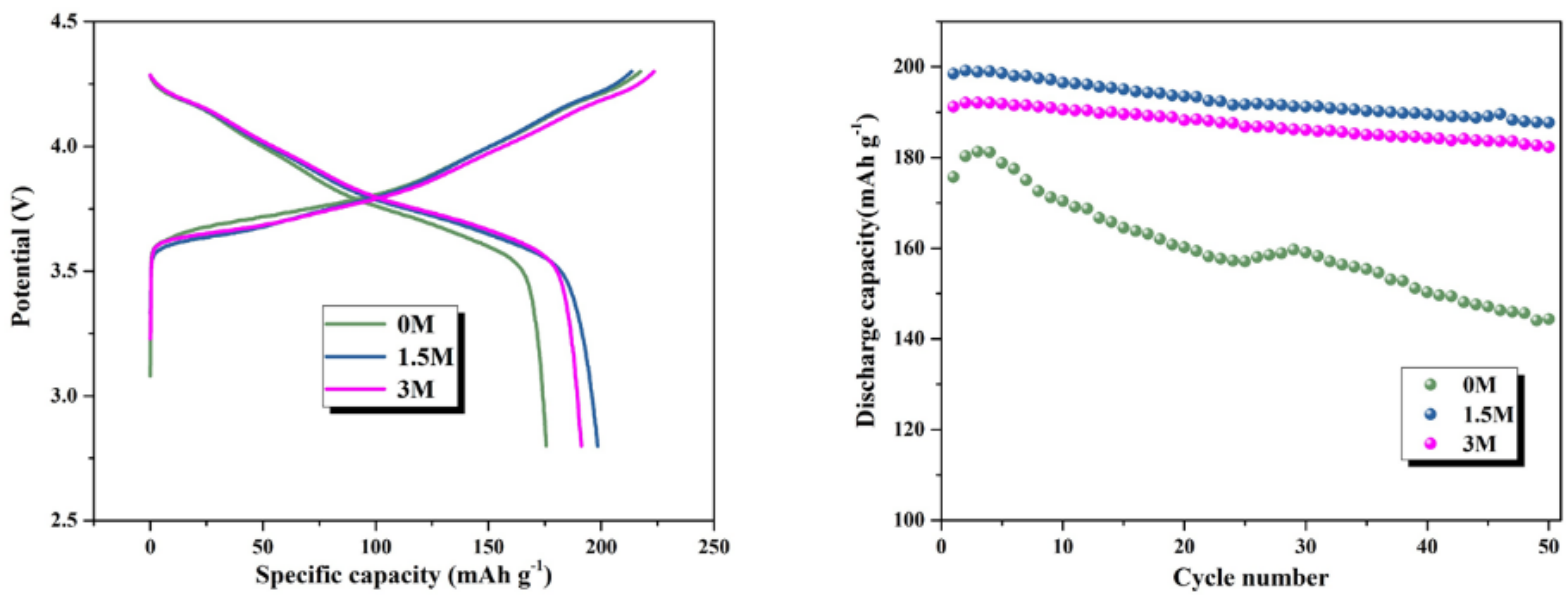

Figure 3. (a) The initial charge and discharge curves; (b) cycling properties at $0.2 \mathrm{C}\left(1 \mathrm{C}=190 \mathrm{~mA} \mathrm{~g}^{-1}\right)$ between 2.8 and $4.3 \mathrm{~V}$ at $30{ }^{\circ} \mathrm{C}$.

The effects of the complexant concentration in base solution on the electrochemical performance for LiNi0.8Co0.1Mn0.1O2 were explored. As shown in Fig. 3a, the initial charge and discharge capacities for samples S1, S1.5 and S3 are 217.4 / 175.7, $213.5 / 198.5$ and 223.5 / $191.2 \mathrm{mAh} \mathrm{g}^{-1}$ with a coulombic efficiency of $80.8 \%, 93.0 \%$ and $85.5 \%$, respectively. The highest reversible discharge capacity and coulombic efficiency of sample S1.5 are attributed to the intimate contact between primary nanoplates and the unobstructed $\mathrm{Li}^{+}$diffusion channels in bulk material. The long term cycling performance is presented in Fig 3b. It shows that S0 electrode suffered a severe capacity faded from 175.7 to $144.4 \mathrm{mAh} \mathrm{g}^{-1}$ after 50 cycles at $0.2 \mathrm{C}$ with only a capacity retention of $82 \%$, whereas the capacity retention of S1.5 and S3 samples up to $95 \%$ after 50 cycles. The poor cycling properties of S0 might due to its smaller particle size and loosely stacked primary nanoplates which result large surface area and serious surface side reaction with electrolyte. On the contrary, the S1.5 and S3 samples have a relatively high tap density and close contact between primary nanoparticles, avoiding the severe side reaction with electrolyte and maintaining the structural integrity during cycling, and thus achieving excellent cycling stability.

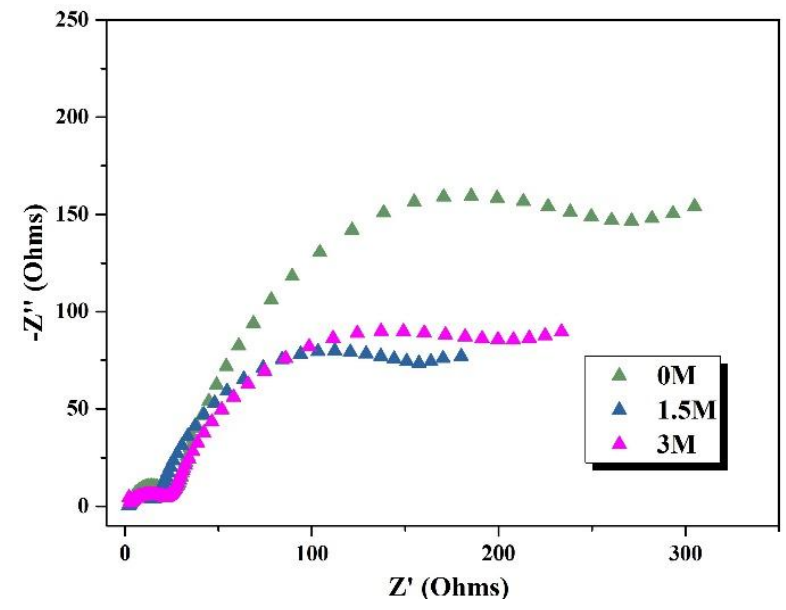

Figure 4. Nyquist plots of the three samples in a charged state of $4.3 \mathrm{~V}$ after the 50th cycles at $0.2 \mathrm{C}$.

To investigate the changes of electrode resistance of different samples, the electrochemical impedance spectra 
(EIS) had been measured in a charged state of $4.3 \mathrm{~V}$ after the 50th cycles at $0.2 \mathrm{C}$, as illustrated in Fig. 4. All of the Nyquist plots displayed an almost same impedance behavior such as a depressed semicircle in the high frequencies which related to the lithium ion migration through the solid-electrolyte interface (SEI) and another depressed semicircle in the middle frequencies which associated with the surface charge transfer process. But, it is obvious that these three electrodes displayed different charge transfer value (the diameter of the second depressed semicircle), and the S1.5 electrode presented a smaller value than the others, which contributed to its excellent cycle performance.

\section{CONCLUSION}

In this study, we synthesized a series of Ni-rich layered $\mathrm{LiNi}_{0.8} \mathrm{Co}_{0.1} \mathrm{Mn}_{0.1} \mathrm{O}_{2}$ by the co-precipitation method through regulating the complexant concentration in base solution. The microstructure, crystalline structure and electrochemical properties were analyzed according to the result of SEM, XRD, HRTEM and battery testing system. It was found that the complexant concentration in base solution seriously affected the particle morphology, size, distribution and the final electrochemical properties. When the complexant concentration in base solution was $1.5 \mathrm{~mol} / \mathrm{L}$, the electrode displayed a high initial discharge capacity of $198.5 \mathrm{mAh} \mathrm{g}^{-1}$, a much more stable capacity retention of $95 \%$ after 50 cycles at $0.2 \mathrm{C}$ rate, and a smaller charge transfer value.

\section{ACKNOWLEDGMENT}

This work was financially supported by the National Key R\&D Program of China for New Energy Vehicle (2016YFB0100400) and Special fund of Beijing Coconstruction Project.

\section{REFERENCES}

[1] J. M. Zheng, W. H. Kan, A. Manthiram, "Role of Mn Content on the Electrochemical Properties of Nickel-Rich Layered $\mathrm{LiNi}_{0.8-} \mathrm{Co}_{0.1} \mathrm{Mn}_{0.1+\mathrm{x}} \mathrm{O}_{2}(0.0 \leq \mathrm{x} \leq 0.08)$ Cathodes for Lithium-Ion Batteries," ACS Appl. Mater. Interfaces, 2015, 7, pp. 6926-6934, doi: 10.1021/acsami.5b00788.

[2] J. Yang, M. Y. Hou, S. Haller, Y. G. Wang, C. X. Wang, Y. Y. Xia, "Improving the Cycling Performance of the Layered Ni-Rich Oxide
Cathode by Introducing Low-Content $\mathrm{Li}_{2} \mathrm{MnO}_{3}$," Electrochim. Acta, 2016, 189, pp. 101-110, doi: 10.1016/j.electacta.2015.12.080.

[3] X. H. Xiong, Z. X. Wang, G. C. Yan, H. J. Guo, X. H. Li, "Role of $\mathrm{V}_{2} \mathrm{O}_{5}$ Coating On $\mathrm{LiNiO}_{2}$-based Materials for Lithium Ion Battery," J. Power Sources, 2014, 245, pp. 183-193, doi: 10.1016/j.jpowsour.2013.06.133.

[4] Y. Kim, J. Cho, "Lithium-Reactive $\mathrm{Co}_{3}\left(\mathrm{PO}_{4}\right)_{2}$ Nanoparticle Coating on High-Capacity $\mathrm{LiNi}_{0.8} \mathrm{Co}_{0.16} \mathrm{Al}_{0.04} \mathrm{O}_{2}$ Cathode Material for Lithium Rechargeable Batteries," J. Electrochem. Soc., 2007, 154, pp. A495-A499, doi: 10.1149/1.2716556.

[5] Y. Yang, S. M. Xu, M. Xie, Y. H. He, G. Y. Huang, Y. C. Yang, "Growth mechanisms for spherical mixed hydroxide agglomerates prepared by co-precipitation method: A case of $\mathrm{Ni}_{1 / 3} \mathrm{Co}_{1 / 3} \mathrm{Mn}_{1 / 3}(\mathrm{OH})_{2}$," Journal of Alloys and Compounds, 2015, 619, pp. 846-853, doi: 10.1016/j.jallcom.2014.08.152

[6] A. v Bommel, J. R. Dahn, "Analysis of the Growth Mechanism of Coprecipitated Spherical and Dense Nickel, Manganese, and CobaltContaining Hydroxides in the Presence of Aqueous Ammonia," Chern Mater, 2009, 21, pp. 1500-1503, doi: 10.1021/cm803144d.

[7] S. Zhang, C. Deng, B. L. Fu, S. Y. Yang, L. Ma, "Synthetic Optimization of Spherical $\mathrm{Li}\left[\mathrm{Ni}_{1 / 3} \mathrm{Mn}_{1 / 3} \mathrm{Co}_{1 / 3}\right] \mathrm{O}_{2}$ Prepared by a Carbonate Co-precipitation Method," Powder Technol., 2010, 198, pp. 373-380, doi: 10.1016/j.powtec.2009.12.002.

[8] M. Noh, J. Cho, "Optimized Synthetic Conditions of $\mathrm{LiNi}_{0.5} \mathrm{Co}_{0.2} \mathrm{Mn}_{0.3} \mathrm{O}_{2}$ Cathode Materials for High Rate Lithium Batteries via Co-precipitation Method," J. Electrochem. Soc., 2013 , 160, pp. A105-A111, doi: 10.1149/2.004302jes.

[9] M. H. Lee, Y. Kang, S. T. Myung, Y. K. Sun, "Synthetic Optimization of $\mathrm{Li}\left[\mathrm{Ni}_{1 / 3} \mathrm{Co}_{1 / 3} \mathrm{Mn}_{1 / 3}\right] \mathrm{O}_{2}$ via Co-precipitation," Electrochim. Acta, 2004, 50, pp. 939-948, doi: 10.1016/j.electacta.2004.07.038.

[10] P. Yue, Z. Wang, X. Li, X. Xiong, J. Wang, X. Wu, H. Guo, "The Enhanced Electrochemical Performance of $\mathrm{LiNi}_{0.6} \mathrm{Co}_{0.2} \mathrm{Mn}_{0.2} \mathrm{O}_{2}$ Cathode Materials by Low Temperature Fluorine Substitution," Electrochimica Acta, 2013, 95, pp. 112-118, doi: 10.1016/j.electacta.2013.02.037.

[11] G. H. Kim, J. H. Kim, S. T. Myung, C.S. Yoon, Y. K. Sun, "Improvement of High-Voltage Cycling Behavior of SurfaceModified Li[ $\left.\mathrm{Ni}_{1 / 3} \mathrm{Co}_{1 / 3} \mathrm{Mn}_{1 / 3}\right] \mathrm{O}_{2}$ Cathodes by Fluorine Substitution for Li-Ion Batteries," Journal of the Electrochemical Society, 2005, 152, pp. A1707-A1713, doi: 10.1149/1.1952747.

[12] P. S. Whitfield, I. J. Davidson, L. M. D. Cranswick, I. P. Swainson, P. W. Stephens, "Investigation of Possible Superstructure and Cation Disorder in the Lithium Battery Cathode Materials $\mathrm{LiNi}_{1 / 3} \mathrm{Mn}_{1 / 3} \mathrm{Co}_{1 / 3} \mathrm{O}_{2}$ Using Neturon and Anomalous Dispersion Powder Diffraction," Solid State Ionics, 2005, 176, pp. 463-471, doi: 10.1016/j.ssi.2004.07.066. 